Revista de Estudios Histórico-Jurídicos

[Sección historia del derecho chileno]

XLIII (Valparaíso, Chile, 2021)

[pp. 519-543]

\title{
LA JuRisPrudencia del Tribunal de Elecciones Municipales de Chile (1865-1888)
}

[The legal doctrine of the Tribunal de Elecciones Municipales of Chile (1865-1888)]

\author{
Gabriel Bocksang Hola* \\ Pontificia Universidad Católica de Chile
}

\begin{abstract}
RESUMEN
La jurisprudencia del Tribunal de Elecciones Municipales de Chile, hoy prácticamente desconocida, contiene elementos sustantivos y procesales importantes. El aporte de dicha jurisprudencia es tanto institucional como dogmático, y su relevancia no se remite a un análisis meramente histórico, sino que también ofrece aspectos de interés al derecho administrativo, electoral y procesal de nuestros días.
\end{abstract}

\footnotetext{
Palabras Clave

Validez-elecciones - municipalidades - Chile - siglo XIX - Tribunales.
}

\begin{abstract}
The legal doctrine of the Tribunal de Elecciones Municipales (Court of Municipal Elections) of Chile, now almost completely unknown, contains important substantive and procedural elements. The influence of this legal doctrine is both institutional and dogmatic, and its relevance is not merely restrained to a historical analysis, also offering relevant aspects to the Administrative Law, the Electoral Law and the Procedural Law of our days.

KEY WORDS

Validity - elections - municipalities Chile $-19^{\text {th }}$ century - Courts.
\end{abstract}

RECIBIDO el 16 de marzo de 2021 y ACEPTADO el 7 de julio de 2021

* Profesor de Derecho Administrativo, Pontificia Universidad Católica de Chile. Dirección postal: Av. Libertador Bernardo O’Higgins 340, Facultad de Derecho, Santiago. Correo electrónico: gbocksan@uc.cl. ORCID: 0000-0002-1608-5323. Este artículo ha sido preparado en ejecución del proyecto ANID (ex CONICYT) Fondecyt/Regular n 1170137, "El derecho administrativo chileno en el período de incorporación de la codificación sustantiva decimonónica (1861-1890)", cuyo investigador responsable es el autor. El autor agradece los valiosos comentarios y sugerencias formulados por los árbitros anónimos de este artículo. 


\section{INTRODUCCIÓN**}

Si bien la historia electoral chilena ha merecido múltiples estudios generales o particulares desde distintas ópticas, como la ciencia política, la estadística o la historia política ${ }^{1}$, todavía existen importantes aspectos de la historia del derecho en esta materia que no han recibido el examen que merecen ${ }^{2}$. Uno de ellos es la existencia en nuestra institucionalidad republicana de un Tribunal de Elecciones Municipales, prácticamente desconocido en la actualidad $^{3}$, pero que tuvo una importante actividad en la segunda mitad del siglo XIX.

Este desconocimiento no debe sorprender. En nuestros días, su presencia no es destacada por obras doctrinales de primera importancia concernientes al estudio de nuestro derecho y nuestras instituciones ${ }^{4}$. Y las escasas obras de nuestro derecho público en el siglo XIX, que, en principio, hubieran sido las más interesadas en analizar la existencia y el funcionamiento de esta entidad, apenas

** Lista de abreviaturas: ANCE. = Archivo Nacional, Archivo del Consejo de Estado; $B L D G .=$ Boletín de Leyes y de Decretos del Gobierno; D. O. = Diario Oficial de la República de Chile; GT. = Gaceta de los Tribunales; TEM. = Tribunal de Elecciones Municipales.

${ }^{1}$ Véase, por ejemplo, Urzúa Valenzuela, Germán, Historia política de Chile y su evolución electoral (desde 1810 hasta 1992) (Santiago, Editorial Jurídica de Chile, 1992); y PONCE DE LEÓN ATRIA, Macarena, Estado y elecciones. La construcción electoral del poder en Chile, siglos XIX y XX, en Jaksić, Iván, Rengifo, Francisca (eds.), Historia política de Chile, 1810-2010. Tomo II: Estado y sociedad (Santiago, Fondo de Cultura Económica, 2017), pp. 243-270.

${ }^{2}$ Los estudios sobre aspectos históricos relevantes en derecho electoral no son frecuentes, pero los ha habido, y hay algunos buenos ejemplos recientes: así, por ejemplo, véase JARA REYES, René, Regularidad electoral, secreto de voto y exclusión. Las tesis dominantes en las memorias de prueba sobre el sufragio en Chile (1897-1920), en REHJ., 39 (2017), pp. 329-349.

${ }^{3}$ Lo que se debe no solo a las lagunas en el análisis jurídico de la historia electoral chilena, sino también a las existentes respecto de la administración municipal decimonónica, lo que no excluye que existan obras que aborden esta materia. Por ejemplo, algunas ofrecen una interpretación general de los municipios en el siglo XIX, como, por ejemplo, SALAZAr Vergara, Gabriel, Historia del municipio y la soberania comunal en Chile, 1820-2016 (Santiago, Editorial Universitaria, 2019), especialmente pp. 13-123; y, por otra parte, otras desarrollan aspectos específicos, como la de Nazer Ahumada, Ricardo, Las finanzas municipales chilenas: 1833-1887, en Historia, 32 (1999), pp. 265-314, o la de RengIFo STREeTER, Francisca, Poder municipal. La territorialización del gobierno estatal en Chile, 1830-1890, en Palimpsesto, 10/17 (2020), pp. 247-266. Pero aún hay territorios importantes por explorar. Baste recordar las expresiones de VALENZUELA, Arturo, Political Brokers in Chile: Local Government in a Centralized Polity (Durham, Duke University Press, 1977), quien, abordando exhaustivamente los municipios durante el siglo XX, lamentaba la falta de estudios analíticos previos acerca de la dimensión local de la política chilena (especialmente en p. x).

${ }^{4}$ V. gr., Bravo LiRa, Bernardino, Historia de las instituciones políticas de Chile e Hispanoamérica (Santiago, Editorial Jurídica de Chile, 1986); Él mismo, El Estado de Derecho en la Historia de Chile (Santiago, Ediciones Universidad Católica de Chile, 1996); EyzAguirre Gutiérrez, Jaime, Historia constitucional de Chile (Santiago, Editorial Universitaria, 1966); HeIse GonZÁlez, Julio, Historia constitucional de Chile (Santiago, Editorial Jurídica de Chile, 1959); UrzÚA VALENZUELA, Germán, Evolución de la administración pública chilena (Santiago, Editorial Jurídica de Chile, 1970). Por su parte, Campos Harriet, Fernando, Historia constitucional de Chile (Santiago, Editorial Jurídica de Chile, 1956), p. 506, apenas menciona que la ley de 1861 "establecía en detalle el proceso que debían seguir las reclamaciones de nulidad de elecciones", sin hacer referencia explícita al Tribunal. 
mencionaban a este Tribunal 5 ; y, a nuestro conocimiento, no hicieron jamás mención de la jurisprudencia que desarrolló.

Lo cierto es que el establecimiento normativo de este Tribunal se produjo originalmente en virtud de una ley especial de $1849^{6}$ por la cual "para conocer de los recursos de nulidad en la elección de municipalidades, se establece dentro del Consejo de Estado un tribunal' (art. $1^{\circ}$ ), cuya integración era compleja: "Lo compondrán los dos consejeros, miembros de las Cortes Superiores de Justicia, un consejero que baya sido Ministro, y dos consejeros que bayan desempeñado los cargos de intendentes, gobernadores o municipales", sirviendo de Fiscal el de la Corte Suprema (art. $2^{\circ}$ ). Esta primera versión del Tribunal parece haber tenido escasísima relevancia jurisdiccional, al punto que, en la década posterior, ni siquiera era mencionada en la obra más importante de derecho procesal de la época ${ }^{7}$.

La Ley de Municipalidades de 1854 no integró primitivamente en su texto a este organismo, pero sí lo hizo una reforma de 1861 a dicha ley ${ }^{8}$, que modificó algunos de los criterios de funcionamiento previstos en el texto anterior y que parece haberle dado a este Tribunal un nuevo impulso. Para facilitar la debida impugnación de los actos que se estimaren ilícitos, dispuso que los reclamos de nulidad se iniciarían " ante el juez. letrado de la provincia en el término perentorio de quince días después de su instalación" (nuevo artículo 146), para que de ellos conociera el Tribunal, que mantendría la integración prevista por la ley de 1849. En materia procesal, se añadió el criterio de que el Tribunal fallaría "sin ulterior recurso" (nuevo artículo 147) y que tendría un plazo máximo de tres meses para resolver la cuestión (nuevo artículo 148). En cuanto a las pruebas, ellas serían recibidas por el juez letrado, "sin perjuicio de la que el mismo tribunal creyere conveniente recibir o mandare practicar de oficio" (nuevo artículo 149).

Bajo la forma establecida en la reforma de 1861, la jurisprudencia de los tribunales ordinarios tuvo oportunidad de declarar formalmente la competencia especial y excluyente del Tribunal de Elecciones en estas materias ${ }^{9}$. Sin embargo, debe tenerse presente que el Consejo de Estado propiamente tal sí intervino en algunas materias electorales que se entendieron no cubiertas por la competencia del Tribunal de Elecciones: así, por ejemplo, la declaración jurisdiccional de no ser municipal un sujeto que, luego de ser electo, declinó su cargo por no cumplir

\footnotetext{
${ }^{5}$ Prado Bustamante, Santiago, Principios elementales de derecho administrativo chileno (Santiago, Imprenta Nacional, 1859), p. 129; HunEeus ZEGERs, Jorge, La Constitución ante el Congreso (Santiago, Imprenta de los Tiempos, 1880), II, p. 238. Y, por lo demás, estas obras no repararon en que una de las primeras sentencias de nuestro derecho administrativo patrio había versado justamente sobre la nulidad de unas elecciones municipales: Junta Superior Gubernativa, 4 y 14 de enero de 1811, Del Villar con Cabildo de Santa Rosa de los Andes, en Archivo Nacional/ Archivo Judicial de Los Andes, 11, pieza 4, f. 3 y 4.

${ }^{6}$ Ley de 28 de agosto de 1849, BLDG., XVII, p. 115.

${ }^{7}$ VILA, Bernardino Antonio, Prontuario de los juicios (Santiago, Imprenta de la Sociedad, 1858).

${ }^{8}$ Ley de 13 de septiembre de 1861, BLDG., XXIX, p. 204.

${ }^{9}$ Corte de Apelaciones de Concepción, 13 de diciembre de 1870, Letelier, GT n ${ }^{\circ} 1508$ [1871], p. 279: "teniendo presente que el conocimiento y resolución de las reclamaciones sobre nulidad de elecciones municipales no corresponden a esta Corte, según lo prescrito en el articulo 147 de la ley de 13 de setiembre de 1861, se declara no haber lugar al recurso de hecho interpuesto a f. 2".
} 
con el tiempo de residencia, lo que había sido aceptado por la Municipalidad ${ }^{10}$; y, por cierto, el hecho de emitir su opinión, no jurisdiccional, por consulta del Supremo Gobierno, lo que cubría también cuestiones electorales, como la consulta acerca de qué hacer si se producía un empate en una elección municipal ${ }^{11}$.

La Ley de Elecciones de $1874^{12}$, manteniendo en vigor al Tribunal, introdujo algunas adecuaciones a su régimen. Reconociendo la proliferación de tribunales, la reclamación se presentaría ante "el juez letrado de turno en lo civil de la provincia" (art. 88). En cuanto a la integración, el Tribunal estaría "compuesto de tres consejeros de Estado, nombrados por el Consejo el primer día de su instalación" (art. 89) $)^{13}$, ampliándose el plazo para resolver las reclamaciones, "bajo la más estricta responsabilidad de sus miembros, dentro de los seis meses siguientes a la fecha en que se bubieren presentado ante ép' (art. 90) ${ }^{14}$, y reconociendo explícitamente el derecho de "los municipales cuya elección se impugna" en orden a hacerse parte en el juicio (art. 91). Mientras rigió la Ley de Municipalidades de 1854, algunas materias electorales distintas, pero bastante próximas, a la de la declaración de nulidad de elecciones municipales, siguieron siendo de competencia del Consejo de Estado. Así, por ejemplo, la resolución de cuestiones concernientes a la nulidad de acuerdos municipales que se hubieran basado sobre un acta electoral adulterada ${ }^{15}$, y la orden de ejecutarse una sentencia del Tribunal de Elecciones por parte de la Municipalidad respectiva ${ }^{16}$.

Mediante la nueva Ley de Elecciones de 1884 se modificaron varios criterios relacionados con estas nulidades ${ }^{17}$. En lo fundamental, y sin perjuicio de ciertos aspectos que se destacarán infra, esta materia se mantuvo bajo la jurisdicción del Tribunal que es objeto de estas líneas (art. 114) y quedó regida por ciertas normas generales aplicables a todo tipo de nulidad electoral (art. 93 a 95), y se alteraron ciertas reglas procesales: el plazo para reclamar pasó a ser de ocho días (art. 113),

${ }^{10}$ Consejo de Estado, 27 de octubre de 1869, Vives con Municipalidad de La Ligua, ANCE., 12, p. 255.

${ }^{11}$ Consejo de Estado, dictamen de 23 de abril de 1870, ANCE., 12, p. 303.

${ }^{12}$ Ley de 12 de noviembre de 1874, BLDG., XLII, p. 317.

${ }^{13} \mathrm{Y}$, por lo tanto, dada la fuente única de integración del Tribunal, incluso los tribunales ordinarios incurrían en el error de considerar que era el Consejo de Estado mismo quien gozaba de competencia en esta materia. Así, por ejemplo, Corte de Apelaciones de Concepción, 29 de diciembre de 1882, Ibánéz con Contreras, GT n 2038 [1882], p. 2004.

${ }^{14}$ Pero debe tenerse presente que este plazo legal, supuestamente establecido en beneficio de los litigantes y de la pronta solución de una situación de incertidumbre, en ocasiones se transformó en un problema. En una oportunidad, el Tribunal, que esperaba la remisión de ciertos antecedentes que supuestamente estaban en poder del juez letrado que había recibido las pruebas correspondientes, no las recibió a pesar de haberlas solicitado con insistencia. Entendiendo el plazo como fatal, dio las infracciones como no probadas al no recibir la información del juez letrado al último día antes del vencimiento del plazo del artículo 90: "finalmente, que el día de boy fija el plazo que el art. 90 de la Ley de Elecciones fija a este tribunal para resolver en las reclamaciones que ante él se entablen". Véase TEM., 15 de abril de 1880, Nulidad de elecciones municipales de Chillán, D. O. $\mathrm{n}^{\circ} 921,16$ de abril de 1880 .

${ }^{15}$ Consejo de Estado, 9 de diciembre de 1879, Sanbueza con Municipalidad de Angol, ANCE., 113, f. 335 vta.; ANCE. 16, p. 259.

${ }^{16}$ Consejo de Estado, 10 de enero de 1880, Miranda Velásquezy otros con Municipalidad de Quinchao, ANCE., 115, f. 363 vta.

${ }^{17}$ Ley de 9 de enero de 1884, BLDG., LIII, p. 59. 
y se previó una pena de multa a los jueces en caso de que el Tribunal excediera de un plazo -reducido, respecto al de 1874- de cien días para resolver (art. 115).

La etapa final del Tribunal fue anunciada por la efímera Ley de Municipalidades de $1887^{18}$ que no hizo referencia a la figura de un tribunal especial, sino que le encomendó el conocimiento de estas cuestiones a la "autoridad judicial", es decir, a la justicia ordinaria, apelándose la cuestión "en la forma ordinaria" (art. $7^{\circ}$ ). Empero, debe tenerse presente que en 1888 aún se ventilaban y juzgaban cuestiones radicadas en el Tribunal de Elecciones Municipales ${ }^{19}$, que gozaba de fundamento normativo a través del artículo 114 la Ley de Elecciones de $1884^{20}$. Este último sustento legal fue finalmente suprimido por la entrada en vigor de una nueva Ley Electoral, la de 1890, que en su artículo 114 señalaba que "las reclamaciones de nulidad que se entablaren contra la elección de municipales se iniciarán en la forma prescrita en la ley de Municipalidades"21, la que, como sabemos, remitía estas materias a la jurisdicción ordinaria. La Ley de Municipalidades de 1891 -la Ley de la Comuna Autónoma ${ }^{22}$ - perseveró en la decisión de su antecesora en torno a evitar una jurisdicción especial, y por ende no restauró al Tribunal de Elecciones Municipales $^{23}$, coincidiendo esta decisión con lo que ha sido calificado como el desplazamiento del foco político principal desde el Ejecutivo hacia el Congreso y las autoridades locales a partir del término de la Guerra Civil de $1891^{24}$.

A pesar de la relativa brevedad de la época en que este Tribunal se mostró activo, y aunque pueden ser bastante adversas tanto la apreciación retrospectiva acerca de esta época de nuestro desarrollo electoral ${ }^{25}$ como aquella que concierne

${ }^{18}$ Ley de 12 de septiembre de 1887, BLDG., LVI, p. 1351.

${ }^{19}$ Las últimas tres sentencias, referidas a elecciones de Lebu y Arauco, son de fecha $1^{\circ}$ de octubre de 1888: TEM., $1^{\circ}$ de octubre de 1888, Nulidad de elecciones municipales de Lebu, ANCE., 123, f. 381, D. O. $\mathrm{n}^{\circ}$ 3416, 10 de octubre de 1888; TEM., $1^{\circ}$ de octubre de 1888, Nulidad de elecciones municipales de Lebu, ANCE., 124, f. 369, D. O. n 3412, 5 de octubre de 1888; TEM., $1^{\circ}$ de octubre de 1888, Nulidad de elecciones municipales de Arauco, D. O. n 3412, 5 de octubre de 1888.

${ }^{20}$ Tan vigentes estaban los criterios competenciales y procesales, que el Tribunal, en una de sus últimas sentencias, desestimó una reclamación que había sido interpuesta ante otro órgano jurisdiccional: "la presente reclamación se ha interpuesto el 7 de abril del año en curso, ante el alcalde que desempeñaba las funciones de juez de primera instancia del departamento, quien ha recibido la información y contrainformación rendidas por las partes; y que, en consecuencia, no tiene valor legal por no haber sido iniciada ante el juez letrado, ni dentro del término fatal de ocho días que prescribe el artículo 113 de la ley de elecciones". Véase TEM., $1^{\circ}$ de octubre de 1888, Nulidad de elecciones municipales de Arauco, D. O. n 3412, 5 de octubre de 1888.

${ }^{21}$ Ley de 20 de agosto de 1890, BLDG., LIX, p. 566.

${ }^{22}$ Ley de 24 de diciembre de 1891, BLDG., LX, p. 336.

${ }^{23}$ Siendo, por lo tanto, muy menor la incidencia del Consejo de Estado en materia de elecciones municipales desde 1891 en adelante; de hecho, apenas una sentencia de dicho Consejo (de fecha 23 de diciembre de 1903) abordará, bajo la ley de la Comuna Autónoma, el tema de las elecciones municipales en general, sin referirse específicamente a la nulidad. Véase CASTILLA, Aurelio, Jurisprudencia del Consejo de Estado (Parral, Imprenta La Democracia, 1919), pp. 249-258.

${ }^{24}$ Valenzuela, Arturo, Political Brokers, cit. (n. 3), p. 192.

${ }^{25}$ V. gr., Bravo LiRA, Bernardino, Historia, cit. (n. 4), p. 141: “en la práctica, todas las elecciones son manejadas por el presidente"; a contrario, VALENZuELA, Julio Samuel, La ley electoral de 1890 y la democratización del régimen politico chileno, en Estudios Públicos, 71 (1998), pp. 265-296, especialmente pp. 268-269, "la ley electoral del 21 de agosto de 1890 tuvo la trascendental 
la viabilidad de las reclamaciones jurisdiccionales electorales en el siglo XIX ${ }^{26}$, estimamos que el organismo jurisdiccional que es objeto de estas líneas merece ser estudiado. Sin perjuicio de su particularidad institucional como único caso de tribunal electoral de tal naturaleza que operó durante este período ${ }^{27}$, y del interés que sobre nuestra historia política puedan aportar las sentencias que pronunció, su interés jurídico reposa, ante todo, en las líneas jurisprudenciales que desarrolló en materia de nulidad electoral, sentando bases remotas de temas que son de debate aun en nuestros días.

Conviene formular una prevención terminológica que, desde el punto de vista técnico, es importante. Dado que las fuentes correspondientes invocan el vocablo $\mathrm{n}$ u $\mathrm{l}$ i d a d en relación con estas materias de infracción electoral, este artículo se apoyará en dicha terminología. Pero debe tenerse en cuenta que dicho término está empleado en este rubro con su acepción vulgar de invalidez en general, y no de nulidad en su sentido técnico. La invalidez de que, bajo el nombre de nulidad, conoció el Tribunal de Elecciones Municipales durante el período en examen era en realidad una anulabilidad ${ }^{28}$, pues solo podía impetrarse por un tiempo determinado ${ }^{29}$.

importancia de contribuir a reformular las prácticas electorales de la época, de tal manera que puede decirse que a partir de entonces el régimen político chileno pasó a cumplir con las exigencias mínimas de una democracia de sufragio incompleto".

${ }^{26} \mathrm{~V}$. gr., Valenzuela, Julio Samuel, Hacia la formación de instituciones democráticas: prácticas electorales en Chile durante el siglo XIX, en Estudios Públicos, 66 (1997), pp. 215-257, especialmente p. 231: "Pero todo ello significaba un esfuerzo considerable que, salvo para los más politizados, quizá no valía la pena".

${ }^{27}$ Si se revisa las leyes electorales de 1861, 1874 y 1884, se advertirá que los reclamos de nulidad de todas las otras elecciones regidas por ellas eran sometidos a conocimiento de alguna de las Cámaras Parlamentarias, o derechamente del Congreso. En ningún caso fueron sometidos a un tribunal formado a partir del Consejo de Estado, como el caso del Tribunal de Elecciones Municipales, ni a otra integración distinta cualquiera. Así, las nulidades correspondientes a elecciones de diputados o senadores eran conocidas por las respectivas cámaras en las leyes de 1861 (art. 130, 133, 134), 1874 (art. 78) y 1884 (art. 96), con diferencias, no obstante, en las respectivas tramitaciones; las de electores del Presidente de la República en la configuración prevista en 1861 eran conocidas por el Senado (art. 141), y de resorte del Congreso bajo las leyes de 1874 (art. 81-82) y de 1884 (art. 103); y, en fin, en las del Presidente de la República el órgano competente fue invariablemente el Congreso según las leyes de 1861 (art. 143), 1874 (art. 83) y 1884 (art. 104).

${ }^{28}$ Respecto al contrapunto técnico entre dos tipos principales de invalidez: la actual, que es la nulidad en sentido estricto, y la potencial, que es la anulabilidad, véase BOCKSANG HoLA, Gabriel, Voidness and voidability of unilateral administrative acts in the Western Tradition, en ROSE-ACKERMAN, Susan - Lindseth, Peter L. - Emerson, Blake (eds.), Comparative Administrative Law (2nd ed., Cheltenham, Edward Elgar, 2017), pp. 420-434, esp. p. 420-422. En torno a la evolución en Occidente de la n u li d a d y sus derivas y oscilaciones históricas, véase, v. gr., Bocksang Hola, Gabriel, L'inexistence juridique des actes administratifs (Paris, Mare \& Martin, 2013), pp. 73-166. Y, en relación con la existencia de la nulidad en sentido estricto en el derecho público decimonónico en Chile, véase Bocksang HolA, Gabriel, El nacimiento del derecbo administrativo patrio de Chile (Santiago, Thomson Reuters, 2015), pp. 588-631.

${ }^{29} \mathrm{La}$ consolidación de la figura de la "nulidad de elecciones" como una anulabilidad parece haberse dado con la ley electoral de 1861, pues ésta fue la que por primera vez a nivel legal exigió que los reclamos se dedujeran en "el término perentorio de quince días" (Ley de 13 de septiembre 
A fin de examinar el aporte jurisprudencial desarrollado por el Tribunal de Elecciones Municipales, abordaremos en primer lugar los aspectos sustantivos relacionados con la nulidad de estos actos (I), para luego examinar los elementos procesales más elaborados a través de la labor jurisdiccional de este organismo (II).

\section{Los ASPECTOS SUSTANTIVOS DE LA NULIDAD DE ELECCIONES MUNICIPALES}

El objeto de las controversias sometidas a conocimiento del Tribunal de Elecciones Municipales revestía una especial importancia, que tuvo un correlato en la labor de análisis desarrollada por esta jurisdicción en torno a sus aspectos capitales. Si, por una parte, son de gran interés los tipos de vicios que, según el Tribunal, podían - o no- dar lugar a una declaración de nulidad de la elección (1), quizás aún más característico fue el empeño de este organismo en torno a dilucidar la influencia de la infracción sobre el resultado de la elección como elemento central para determinar la eventual declaración de nulidad (2).

\section{Los tipos de vicios conducentes a la declaración de nulidad}

Un aspecto primordial en torno a la actividad jurisprudencial del Tribunal de Elecciones Municipales está dado por la determinación de los tipos de vicios que habilitan a una declaración de nulidad. Desde una perspectiva política, es sin duda el elemento más llamativo y que más puede colaborar a comprender institucionalmente la comprensión de las miradas que en la época señalada se vertían sobre los ilícitos electorales.

Una primera constatación que debe tenerse presente en esta materia es la importante cantidad de declaraciones de nulidad pronunciadas en estos juicios. Es probable que un buen número de irregularidades no haya llegado a conocerse por el Tribunal de Elecciones Municipales; pero de las que llegaron a él consta que en no pocas veces se declaró la nulidad. Es más; atendidas las sentencias examinadas, hasta las elecciones de 1886 inclusive la situación muestra un número equilibrado de sentencias declaratorias de validez y de nulidad, y en algunos procesos eleccionarios estas últimas fueron más numerosas que las primeras. Solo en los pleitos referidos a las elecciones municipales de 1888 hemos constatado un acentuado desnivel por las declaraciones de validez en desmedro de las declaraciones de nulidad ${ }^{30}$.

Los tipos de vicios que dieron lugar a estas declaraciones fueron, además, de bastante variada índole. Ello se articula bien con el hecho de que en ninguna de las normas que rigieron a este órgano colegiado existiera alguna disposición que enumerase taxativamente los vicios que dieran lugar a la declaración de nulidad de elecciones. Cuando mucho, las leyes, más que señalar una casuística de las transgresiones a la juridicidad electoral, explicitaban que las distintas etapas del

de 1861, BLDG., XXIX, p. 204, art. 146). En la ley de 28 de agosto de 1849, BLDG., XVII, p. 115 , ningún plazo de prescripción se había previsto para entablar el reclamo.

${ }^{30}$ Entre las cuestiones ventiladas de 1888 hubo doce declaraciones de validez de las elecciones (Chañaral, Ancud, Valdivia en dos ocasiones, Rere, Temuco, Lautaro, Arauco en dos ocasiones, Melipilla, y Lebu en dos ocasiones), y una sola declaración de nulidad (Collipulli). 
procedimiento electoral estaban incorporadas en la arquitectura de esta acción. La Ley Electoral de 1861 disponía, en relación con cualquier tipo de actos electorales, que se podría reclamar de nulidad por actos que hubieran viciado las elecciones "sea en la constitución o procedimientos de las mesas receptoras, sea en el escrutinio parcial de cada día de elección o en el general que practicare la Municipalidad, sea por actos de personas extrañas a la mesa o juntas que deben practicar el escrutinio" "31, redacción que fue seguida muy de cerca por las dos leyes electorales sucesivas de $1874^{32}$ y $1884^{33}$.

Por ello es que, como es esperable, fue la propia jurisprudencia del Tribunal de Elecciones Municipales la que fue delineando los contornos de los vicios que conducían a una declaración de nulidad. El repertorio de situaciones, como se verá, no fue para nada desdeñable.

Algunos forman parte de las situaciones más extendidamente conocidas como infracciones electorales. Así, la destrucción de los sufragios que contenía una urna ilícitamente abierta ${ }^{34}$, la adulteración de las actas electorales ${ }^{35}$, o derechamente el robo de una urna y los registros correspondientes: "del acta citada aparece también que no ha habido elección en las mesas de las secciones primera y segunda de la subdelegación octava, primera de la subdelegación novena, primera de la subdelegación diecinueve, ni en la de la subdelegación sétima rural, las cuales fueron asaltadas por turbas que les arrebataron las urnas y los registros" ${ }^{36}$. En otras ocasiones, más que desaparecer, había votos que ilícitamente aparecían: "por el hecho de haber puesto un vocal fraudulentamente un paquete de votos en la urna, no deben tomarse en cuenta los cincuenta y seis votos de aquella mesa que en su totalidad correspondieron a los candidatos proclamados" ${ }^{37}$. Y las infracciones podían extenderse incluso al ámbito político, como el caso en que un subdelegado impidió ilícitamente con la fuerza pública la realización de un acto electoral, lo que conllevó ordenarse su procesamiento penal ${ }^{38}$.

${ }^{31}$ Ley de 13 de septiembre de 1861, BLDG., XXIX, p. 204, art. 127.

${ }^{32}$ Ley de 12 de noviembre de 1874, BLDG., XLII, p. 317, art. 73: "sea en la constitución o procedimientos de las juntas de mayores contribuyentes o de las juntas calificadoras o receptoras, sea en el escrutinio parcial de cada sección o en general que practicare la junta escrutadora, sea por actos de personas extrañas a la elección".

${ }^{33}$ Ley de 9 de enero de 1884, BLDG., LIII, p. 59, art. 93: "sea en la organización o procedimientos de la junta de contribuyentes, de las comisiones ejecutivas de calificación o de elección, de las juntas calificadoras o receptoras, sea en el escrutinio parcial de cada sección o en el general que practicare la junta escrutadora, sea por actos de personas extrañas a la elección".

${ }^{34}$ TEM., 4 de enero de 1865, Nulidad de elecciones municipales de Los Andes, ANCE., 106, f. 31.

${ }^{35}$ TEM., 12 de junio de 1877, Nulidad de elecciones municipales de San Javier, D.O. $\mathrm{n}^{\circ}$ 89, 18 de junio de 1877. También TEM., 10 de noviembre de 1882, Nulidad de elecciones municipales de Valparaíso, D. O. n 1681, 13 de noviembre de 1882. Correlativamente, no es lícito impugnar una elección valiéndose de actas adulteradas: TEM., 28 de septiembre de 1888, Nulidad de elecciones municipales de Lautaro, D. O. $\mathrm{n}^{\circ} 3408,1^{\circ}$ de octubre de 1888.

${ }^{36}$ TEM., 21 de octubre de 1886, Nulidad de elecciones municipales de Santiago, ANCE., 122, f. 415, D. O. $\mathrm{n}^{\circ} 2844,27$ de octubre de 1886.

${ }^{37}$ TEM., 21 de octubre de 1886, Nulidad de elecciones municipales de Putaendo, ANCE., 121, $\mathrm{f}$. 76, D. O. n ${ }^{\circ} 2844,27$ de octubre de 1886.

${ }^{38}$ TEM., 12 de junio de 1877, Nulidad de elecciones municipales de San Javier, D.O. n 89, 18 de junio de 1877. Pero debe tenerse en cuenta que el llamarse a la fuerza pública por las autoridades competentes no era por sí mismo motivo de nulidad, máxime si no se impedía el sufragio de los 
Una segunda categoría de infracciones está dada por las vulneraciones a la composición de los órganos electorales. Tal fue el caso de la composición de Juntas de Mayores Contribuyentes en infracción a la ley ${ }^{39}$, así como la composición de mesas receptoras con sujetos no habilitados para ello ${ }^{40} \mathrm{o}$ sin la mayoría absoluta de sus miembros ${ }^{41}$.

Otros vicios se desprenden de las dificultades especiales que, por distintos motivos, condicionaron el desarrollo de los actos electorales. Por ejemplo, la reducción de los horarios de votación, a cuatro horas y media de las seis preestablecidas ${ }^{42}$, o incluso a dos horas un día y a cinco horas otro día, "sin que ocurriera ninguna de las circunstancias especiales que autorizan ese procedimiento"43. También en esta categoría puede contemplarse la "preferencia para admitir los votos del partido de que eran candidatos el presidente y la mayor parte de los vocales de la mesa receptora, a cuyo efecto se habian marcado exteriormente las listas con signos que se veian desde lejos; mientras que se demoraba y dificultaba de diversos modos la recepción de los votos del partido contrario", advirtiéndose además en dichos sucesos el uso de la fuerza pública para evitar el voto de personas afines a sus contrincantes políticos ${ }^{44}$. Asimismo, el caso del funcionamiento de la junta receptora de sufragios en otro local que el designado por la junta de mayores contribuyentes ${ }^{45}$, aunque en otro litigio posterior se expresó que el cambio de lugar de votación por sí solo no bastaba para la declaración de nulidad $^{46}$. Y, por último, el caso del desarrollo del acto electoral el día posterior al oficialmente previsto ${ }^{47}$.

Un cuarto tipo de causales se relaciona con las discordancias numéricas existentes entre las distintas actuaciones relacionadas con el procedimiento electoral. Tal es el caso en que la cantidad de votos excede a la cantidad de personas cali-

votantes, como aparece de TEM., 5 de julio de 1877, Nulidad de elecciones municipales de Quillota, D.O. $\mathrm{n}^{\circ} 110,13$ de julio de 1877.

${ }^{39}$ TEM., 15 de mayo de 1877, Nulidad de elecciones municipales de Canquenes, ANCE., 112, $\mathrm{f}$. 234; TEM., 12 de enero de 1883, Nulidad de elecciones municipales de Vallenar, ANCE., 118, f. 49, D. O. $\mathrm{n}^{\circ} 1729,15$ de enero de 1883; TEM., $1^{\circ}$ de octubre de 1885, Nulidad de elecciones municipales de Curepto, ANCE., 37, p. 30, ANCE., 120, f. 7, D. O. n² 2532, 5 de octubre de 1885. Pero no se consideró como infracción el que la junta de mayores contribuyentes sesionase en otra sala que la municipal: TEM., 29 de septiembre de 1888, Nulidad de elecciones municipales de Arauco, D. O. $\mathrm{n}^{\circ} 3411,4$ de octubre de 1888 .

${ }^{40}$ TEM., 11 de mayo de 1877, Nulidad de elecciones municipales de Lautaro, ANCE., 111, f. 477.

${ }^{41}$ TEM., 27 de septiembre de 1888, Nulidad de elecciones municipales de Collipulli, D. O. $\mathrm{n}^{\circ} 3407$, 29 de septiembre de 1888 .

${ }^{42}$ TEM., 22 de diciembre de 1865, Nulidad de elecciones municipales de Lontué, en LARRAín ZaÑARTu, Ignacio y Joaquín, Boletín de las principales leyes y decretos vigentes dictados desde enero $1^{\circ}$ de 1860 basta enero $1^{\circ}$ de 1871 (Valparaíso, Imprenta del Mercurio, 1871), p. 19.

${ }^{43}$ TEM., 4 de noviembre de 1879, Nulidad de elecciones municipales de Copiapó, ANCE., 114, f. 88.

${ }^{44}$ TEM., 22 de diciembre de 1865, Nulidad de elecciones municipales de Lontué, en LARRAíN ZaÑARTu, Ignacio y Joaquín, Boletin de las principales leyes y decretos vigentes dictados desde enero $1^{\circ}$ de 1860 basta enero $1^{\circ}$ de 1871 (Valparaíso, Imprenta del Mercurio, 1871), p. 19.

${ }^{45}$ TEM., 4 de noviembre de 1879, Nulidad de elecciones municipales de Copiapó, ANCE., 114, f. 88.

${ }^{46}$ TEM., 20 de septiembre de 1888, Nulidad de elecciones municipales de Chañaral, D. O. $\mathrm{n}^{\circ}$ 3405, 27 de septiembre de 1888.

${ }^{47}$ TEM., 10 de enero de 1884, Nulidad de elecciones municipales de Vallenar, ANCE., 118, f. 417, D. O. n n $^{\circ} 2028,16$ de enero de 1884. 
ficadas para la elección respectiva ${ }^{48}$, o en que hay un mayor número de votantes en el acta que en la urna ${ }^{49}$, o en que no coinciden los escrutinios parciales con el escrutinio general ${ }^{50}$.

En quinto lugar, se puede hallar infracciones relacionadas con la publicidad del acto electoral. Ello puede suceder bajo condiciones más bien generales, como en el caso en que los "escrutinios se han practicado sin la publicidad prescrita por la ley" ${ }^{\prime \prime}$, pero también respecto de medidas de publicidad referidas a aspectos más específicos, como la falta de declaración de que la urna se encontrara vacía al inicio de la votación ${ }^{52}$.

En sexto lugar, cabe enunciar los casos de ausencia de ciertos actos electorales de relieve. Ello podía constatarse en situaciones de distinta amplitud, desde la falta de cómputo de algunas mesas - que, según una sentencia, habilitaba para declarar nulo el escrutinio, pero no el acto electoral en su conjunto ${ }^{53}$-, hasta la ausencia abierta de sufragio en algunas localidades de la unidad territorial respectiva ${ }^{54}$.

$\mathrm{Y}$, por último, conviene destacar ciertos casos de infracciones que fueron desestimadas por el Tribunal de Elecciones Municipales como conducentes a una declaración de nulidad. Tales son la falta de un miembro de la mesa receptora ${ }^{55}$; el hecho de haberse impedido la presidencia de los alcaldes en la junta escrutadora $^{56}$; el cuestionamiento sobre la entrada en funciones de un alcalde suplente, entendiéndose que por más que este participara en las funciones electorales correspondientes, "la designación de un alcalde no es acto electorap" 57 ; la falta de la mención "votó" en los boletos de calificación ${ }^{58}$; y el caso, llamativo, por decir lo menos, de la coexistencia de tres procesos eleccionarios, sin poder determinarse cuál de todos era el viciado: "aun cuando el hecho solo de haberse efectuado tres elecciones simultáneas en un mismo departamento basta para formar certidumbre de que todas ellas, o dos por lo menos de esas elecciones, adolecen de nulidad, no es posible, con todo, proceder a declararlo así, sin saber de una manera precisa cuál o cuáles de entre ellas adolecen realmente de vicios que

${ }^{48}$ TEM., 15 de mayo de 1877, Nulidad de elecciones municipales de Cauquenes, ANCE., 112, f. 234.

${ }^{49}$ TEM., 21 de octubre de 1886, Nulidad de elecciones municipales de Putaendo, ANCE., 121, $\mathrm{f}$. 76, D. O. $\mathrm{n}^{\circ} 2844,27$ de octubre de 1886.

${ }^{50}$ TEM., 4 de mayo de 1880, Nulidad de elecciones municipales de San Felipe, ANCE., 114, f. 452, D. O. n 939, 8 de mayo de 1880 .

${ }^{51}$ TEM., 21 de octubre de 1886, Nulidad de elecciones municipales de Santiago, ANCE., 122, f. 415, D. O. $\mathrm{n}^{\circ} 2844,27$ de octubre de 1886.

${ }^{52}$ TEM., 4 de mayo de 1880, Nulidad de elecciones municipales de San Felipe, ANCE., 114, f. 452, D. O. n 939, 8 de mayo de 1880 .

${ }^{53}$ TEM., 20 de noviembre de 1882, Nulidad de elecciones municipales de Talca, ANCE., 116, $\mathrm{f}$. 200, D. O. n ${ }^{\circ} 1689,22$ de noviembre de 1882.

${ }^{54}$ TEM., 7 de octubre de 1885, Nulidad de elecciones municipales de La Unión, ANCE., 37, p. 25, ANCE., 119, f. 285, D. O. n² 2541, 15 de octubre de 1885.

${ }^{55}$ TEM., 26 de octubre de 1870, Nulidad de elecciones municipales de Freirina, ANCE., 108, f. 115.

${ }^{56}$ TEM., 26 de octubre de 1883, Nulidad de elecciones municipales de Parral, ANCE., 118, f. 95, D. O. $\mathrm{n}^{\circ} 1962,27$ de octubre de 1883 .

${ }^{57}$ TEM., 5 de julio de 1877, Nulidad de elecciones municipales de Quillota, D.O. $\mathrm{n}^{\circ} 110,13$ de julio de 1877.

${ }^{58}$ TEM., 20 de enero de 1883, Nulidad de elecciones municipales de La Ligua, ANCE., 117, f. 448, D. O. n ${ }^{\circ} 1735,22$ de enero de 1883. 
las anulen" 59 . También, por causas extrínsecas al acto eleccionario, pero de sumo interés para el derecho administrativo decimonónico, se desestimó como causal de nulidad el hecho de haber intervenido en distintas actuaciones un alcalde al que por acuerdo municipal se le había declarado impedido para desempeñar sus funciones, acuerdo al que sin embargo se había opuesto el Gobernador, y que por lo tanto, de acuerdo a la Constitución y a la ley vigente "quedó él sin efecto hasta tanto no se determinase por el Consejo de Estado el valor legal que ese acuerdo debia tener", con lo que las actuaciones del alcalde debían tenerse por lícitas ${ }^{60}$.

\section{La influencia en el resultado de la elección}

La mera existencia de un vicio en materia electoral, de acuerdo con la jurisprudencia del Tribunal de Elecciones Municipales, en general no bastaba para que pudiera declararse la nulidad de la elección. Se requería también que el vicio hubiera tenido "infuencia en el resultado de la elección". Este aspecto práctico de la nulidad ha sido recogido desde hace mucho por distintos ordenamientos jurídicos: la idea atrás de ello es la de "no acoger jamás nulidades inútiles" ${ }^{61}$.

Este requisito fue establecido por vía legislativa, de modo general para todo tipo de elecciones, en las leyes electorales respectivas. En esto confluyen dos disposiciones principales. Por una parte, la fórmula "y que puedan influir en que la elección dé un resultado diferente del que debia ser consecuencia de la libre y regular manifestación del voto de los electores", original de la ley de $1861^{62}$, que fue reproducida en las leyes electorales de 1874 y de $1884^{63}$, y que expresa positivamente el requisito de influencia ${ }^{64}$. Por otra parte, la expresión negativa de este mismo requisito, en un artículo complementario que también tiene su génesis en la ley de 1861: “los hechos o defectos o irregularidades que no influyan en el resultado general de la elección, sea que hayan ocurrido durante la votación o durante los actos que se ejecutan hasta proclamar los electos, no dan mérito para declarar la nulidad" ${ }^{\prime 6}$. Sin embargo, esta disposición, contrariamente a la anterior, sí fue objeto de algunos ajustes en las leyes sucesivas. En 1874 se añadió la mención a los hechos, actos o irregularidades ocurridas antes

${ }^{59}$ TEM., 31 de agosto de 1880, Nulidad de elecciones municipales de Constitución, ANCE., 114, f. $367, D$. O. $\mathrm{n}^{\circ} 1039,4$ de septiembre de 1880. Esta jurisprudencia es contradictoria con la que declaró nulas las elecciones en que se desarrollaran simultáneamente dos procesos electorales, que se aborda infra, II.2.

${ }^{60}$ TEM., 28 de abril de 1877, Nulidad de elecciones municipales de Vichuquén, ANCE., 111, f. 90.

${ }^{61}$ Solon, Victor-Hippolyte, Théorie sur la nullité des conventions et des actes de tout genre en matière civile (Paris, Videcoq et Barba, 1835), p. xiv. La traducción es nuestra.

${ }^{62}$ Ley de 13 de septiembre de 1861, BLDG., XXIX, p. 204, art. 127.

${ }^{63}$ Ley de 12 de noviembre de 1874, BLDG., XLII, p. 317, art. 73; Ley de 9 de enero de 1884, BLDG., LIII, p. 59, art. 93.

${ }^{64} \mathrm{Y}$ que tuvo, a pesar de su carácter más indeterminado, recepción en jurisprudencia: véase TEM., 22 de diciembre de 1865, Nulidad de elecciones municipales de Lontué, en LARRAín ZAÑARTU, Ignacio y Joaquín, Boletín de las principales leyes y decretos vigentes dictados desde enero $1^{\circ}$ de 1860 basta enero $1^{\circ}$ de 1871 (Valparaíso, Imprenta del Mercurio, 1871), p. 19. También TEM., 21 de octubre de 1886, Nulidad de elecciones municipales de Santiago, ANCE., 122, f. 415, D. O. n ${ }^{\circ} 2844,27$ de octubre de 1886; y TEM., 29 de septiembre de 1888, Nulidad de elecciones municipales de Melipilla, ANCE., 123, f. 277, D. O. n 3411, 4 de octubre de 1888.

${ }^{65}$ Ley de 13 de septiembre de 1861, BLDG., XXIX, p. 204, art. 128. 
de la votación ${ }^{66}$, mientras que en 1884 se añadió, a continuación de la fórmula en su versión de 1874, un inciso en que se preveía un caso de nulidad forzosa: "sin embargo, se declararán siempre nulos los actos de las juntas o comisiones que bubieren funcionado sin la mayoría absoluta de sus miembros" ${ }^{97}$.

El requisito de influencia en el resultado general de la elección tuvo significativa incidencia en el número de declaraciones de nulidad electoral pronunciadas por el Tribunal, pues en varias oportunidades se desestimaron los reclamos justamente por la constatación de la falta de influencia. Aunque en ocasiones la expresión de esta carencia era más bien formal ${ }^{68}$, en otras oportunidades se manifestaba un análisis más detenido de esta materia.

Por ejemplo, en materia de integración de la Junta receptora, bajo el imperio de la ley de 1874 se juzgó que "si es verdad que la Junta receptora de la sección mencionada no estuvo constantemente compuesta de los miembros que, según la ley, debian formarla, y que solo dos de ellos bicieron el escrutinio por la ausencia de los demás, es también cierto que no se ha establecido ni acreditado que estas irregularidades hayan dado por resultado la suplantación o alteración de los sufragios emitidos, ni que los electores hayan tenido el propósito de favorecer con sus sufragios a candidatos distintos de los que aparecen del acta" ${ }^{\prime \prime}$.

También se estimó no haber tenido influencia en el resultado general de la elección el hecho de "baberse instalado dos de las mesas receptoras objetadas en lugares inmediatos a los fijados por la Comisión Ejecutiva" ${ }^{70}$. En este caso, el carácter inmediato de esta ubicación parece haber sido decisivo para la posición del Tribunal, dado que en otra oportunidad se había juzgado que el cambio de ubicación de las mesas sí era un elemento relevante ${ }^{71}$.

Estas dos situaciones referidas como no influyentes en el resultado de la elección bien pudieron, como puede advertirse, haber propiciado una declaración en sentido contrario. Por ello, el requisito de influencia en el resultado general de la elección, más que integrarse como un criterio cualitativo, correspondiente a ciertos tipos de comportamientos, se consolidó cuantitativamente como un criterio de ponderación numérica.

Así, por ejemplo, en una de las primeras sentencias pronunciadas por este organismo, la desaparición de la urna del segundo día de votación se entendía como relevante para estos efectos en atención a que el número de votantes del primer día era muy inferior al del total de calificados que no habían votado en dicha oportunidad ${ }^{72}$.

Pero en otras sentencias se advierte que la influencia en el resultado de la elección era un criterio riguroso y más bien restringido a lo estrictamente nece-

${ }^{66}$ Ley de 12 de noviembre de 1874, BLDG., XLII, p. 317, art. 74.

${ }^{67}$ Ley de 9 de enero de 1884, BLDG., LIII, p. 59, art. 94. Véase TEM., 27 de septiembre de 1888, Nulidad de elecciones municipales de Collipulli, D. O. n 3407, 29 de septiembre de 1888.

${ }^{68}$ TEM., 10 de octubre de 1885, Nulidad de elecciones municipales de Castro, ANCE., 37, p. 36, ANCE., 119, f. 239, D. O. n ${ }^{\circ} 2553,29$ de octubre de 1885.

${ }^{69}$ TEM., 24 de abril de 1877, Nulidad de elecciones municipales de Casablanca, ANCE., 111, f. 375.

${ }^{70}$ TEM., 27 de septiembre de 1888, Nulidad de elecciones municipales de Rere, ANCE., 124, f. 239, D. O. n 3407,29 de septiembre de 1888.

${ }^{71}$ TEM., 4 de noviembre de 1879, Nulidad de elecciones municipales de Copiapó, ANCE., 114, f. 88.

${ }^{72}$ TEM., 4 de enero de 1865, Nulidad de elecciones municipales de Los Andes, ANCE., 106, f. 31. 
sario. Quizá el caso más puro de esta apreciación está dado por una sentencia de 1883 que dispuso lo siguiente, por no haberse computado ciertas mesas: "aun eliminando los votos que obtuvo don Felipe Erazo en las secciones de El Ingenio del total con que aparece en el acta del escrutinio general, queda siempre con trescientos cuarenta votos, lo que le daría diez de mayoría sobre el que bubiera obtenido la unanimidad de las dos secciones de El Ingenio" "73. Es decir, por más grave que hubiera sido la infracción, de modo de eliminar todos los votos sospechados como contrarios a derecho, el resultado no hubiera variado; y por lo tanto no se da lugar a la declaración de nulidad. Igual decisión se adoptaba frente a infracciones en el escrutinio que finalmente terminaran siendo numéricamente irrelevantes en la práctica: "aun aceptando la suposición extrema de que esos cuarenta y ocho votos bubieran sido todos favorables a la lista que obtuvo mayoria, y rebajándolos al municipal proclamado que obtuvo menor número de sufragios entre los propietarios que fue don Ramón Subercaseaux, este quedaría con 153 votos y excedería por tanto en cuatro a los candidatos de la lista de la minoría que reunieron mayor número de sufragios" 74 .

Como contrapartida, si de alguna manera la infracción hubiera podido afectar el resultado, aun cuando no existiera claridad acerca de cuál específicamente hubiera sido la variación y cuáles específicamente hubieran sido los municipales electos, el Tribunal en un principio dio lugar a la declaración de nulidad ${ }^{75}$. Por lo mismo, en un principio se estimó que no era necesario que la infracción afectase a todos los candidatos, bastando con que se alterase el resultado respecto de algunos de ellos ${ }^{76}$.

Dicha jurisprudencia, sin embargo, sería revertida hacia el final del período de actividad de este órgano, a partir de una sentencia de 1888 en que se señaló que "la falta de votación de la indicada mesa, atendido el numero de los inscritos en ese registro, ha podido influir únicamente respecto de la elección de los dos últimos municipales proclamados [...] y que, por consiguiente, el hecho de no haber sufragado los 89 inscritos por el no funcionamiento de la mesa de las subdelegaciones $9^{a}$ y $10^{a}$ no ha influido en el resultado general de la elección" ${ }^{77}$. Si alguna duda hubiera podido caber respecto del designio de tales expresiones, pocos días después el Tribunal pronunció otra sentencia que dispuso que "el no funcionamiento de la mesa de la subdelegación de 'María Pinto', en cuyo registro bay inscritos

${ }^{73}$ TEM., 20 de enero de 1883, Nulidad de elecciones municipales de La Ligua, ANCE., 117, f. 448, D. O. n n $^{\circ} 1735,22$ de enero de 1883.

${ }^{74}$ TEM., 31 de agosto de 1885, Nulidad de elecciones municipales de Viña del Mar, ANCE., 37, p. 16, ANCE., 120, f. 222, D. O. n 2515, 11 de septiembre de 1885. También véase TEM., 20 de agosto de 1885, Nulidad de elecciones municipales de Valparaíso, ANCE., 37, p. 12, ANCE., 120, f. $130, D . O . n^{\circ} 2502,26$ de agosto de 1885 .

${ }^{75}$ TEM., 7 de octubre de 1885, Nulidad de elecciones municipales de La Unión, ANCE., 37, p. 25, ANCE., 119, f. 285, D. O. n² 2541, 15 de octubre de 1885.

${ }^{76}$ TEM., 4 de mayo de 1880, Nulidad de elecciones municipales de San Felipe, ANCE., 114, f. 452, D. O. $\mathrm{n}^{\circ}$ 939, 8 de mayo de 1880. También en TEM., 3 de diciembre de 1883, Nulidad de elecciones municipales de Llanquibue, D. O. $\mathrm{n}^{\circ}$ 1996, 7 de diciembre de 1883); y en TEM., 21 de octubre de 1886, Nulidad de elecciones municipales de Putaendo, ANCE., 121, f. 76, D. O. $\mathrm{n}^{\circ} 2844$, 27 de octubre de 1886.

${ }^{77}$ TEM., 20 de septiembre de 1888, Nulidad de elecciones municipales de Valdivia (1 ${ }^{a}$ sentencia), D. O. $\mathrm{n}^{\circ} 3406,28$ de septiembre de 1888 . 
ciento diezy siete electores, no influye en el resultado general de la elección, porque ese número de votos solo podria haberla hecho variar respecto de los tres últimos municipales proclamados"78.

Esta solución apunta a una reinterpretación de la fórmula "resultado general", que transitó desde el sentido de resultado total hacia el sentido de resultado mayoritario. Así aparece en el voto disidente del ministro Valenzuela Castillo a la sentencia de las elecciones municipales de Melipilla, que con toda claridad expresa creer que "en contraposición a la opinión de los demás miembros del Tribunal, que para que un acto influy a en el resultado general de la elección no es necesario que influy a en la totalidad o mayor parte de las personas que forman la lista de los proclamados, sino en el resultado general de las elecciones parciales que se verifican en cada mesa o sección del registro. En consecuencia, es de opinión que, cuando el acto, defecto o irregularidad pueda hacer variar el resultado de ese conjunto de elecciones parciales que constituye el resultado general, debe declararse nula la elección del municipal o municipales a quienes aquellos puedan afectar, lo que en el caso presente sucede con los tres a que antes me he referido" 79 .

El Tribunal tuvo oportunidad de abordar este punto una vez más en una sentencia posterior, y su solución fue exactamente la misma que viene de expresarse, aunque verificada de un modo aún más terminante: "la presente reclamación se refiere solo a cinco de los dieciocho municipales proclamados para el departamento de Lebu, y que, en consecuencia, aun dando por comprobados los hechos en que ella se funda, ellos no han influido en el resultado general de la elección" 80 . En términos prácticos, lo anterior significa que el Tribunal consideraba como irrelevante cualquier reclamación parcial sobre los resultados; para que pudiera darse lugar a una declaración de nulidad, se requería una reclamación total, que, además, para declararse la nulidad, debía conducir a una alteración de la mayoría de los electos.

El ministro Valenzuela Castillo insistió en su posición disidente a través de un voto particular ${ }^{81}$, que estimamos ser la correcta frente a esta norma, por ser la que recoge el respeto de un criterio de justicia en orden al bien común, a la justicia distributiva, y a las perspectivas indeterminadas de las consecuencias de la elección de una persona u otra durante el lapso de su función, tanto desde una perspectiva jurídica como una perspectiva política. La desaparición del Tribunal truncó una evolución más larga, y controversias más desarrolladas, en torno a los debates sobre este importante punto hermenéutico.

\section{LOS ASPECTOS PROCESALES DE LA NULIDAD DE ELECCIONES MUNICIPALES}

En el ámbito procesal, las materias abordadas por la jurisprudencia del Tribunal de Elecciones Municipales fueron bastante variadas, y dan cuenta de la preocupación de este órgano jurisdiccional en orden a promover una actividad dotada

${ }^{78}$ TEM., 29 de septiembre de 1888, Nulidad de elecciones municipales de Melipilla, ANCE., 123, f. $277, D . O . \mathrm{n}^{\circ} 3411,4$ de octubre de 1888 .

${ }^{79}$ ANCE., 123, f. 282.

${ }^{80}$ TEM., $1^{\circ}$ de octubre de 1888, Nulidad de elecciones municipales de Lebu, ANCE., 123, f. 381, D. O. $\mathrm{n}^{\circ} 3416,10$ de octubre de 1888 .

${ }^{81}$ ANCE., 123, f. 382 vta. 
de parámetros consistentes. A fin de tratarlas convenientemente, examinaremos en primer lugar las cuestiones referidas al desenvolvimiento del proceso (1), para luego detenernos específicamente en el tema de las sentencias que resolvían el problema de la nulidad de las elecciones municipales (2).

\section{El desarrollo del proceso jurisdiccional}

Quizás un aspecto preliminar que debiese destacarse en torno los aspectos procesales de este tipo de procedimientos es uno tácito, no desarrollado por ninguna de las sentencias ni tampoco evocado por las leyes respectivas. Se trata del hecho de que no se rigieron, al menos explícitamente, por ninguno de los grandes cuerpos normativos patrios que ordenaban materias procesales. Así, en las primeras sentencias, jamás se constata una alusión al Reglamento de Administración de Justicia de $1824^{82}$; y a partir del $1^{\circ}$ de marzo de 1876 , fecha de entrada en vigor de la Ley de Organización y Atribuciones de los Tribunales, tampoco se expresó por el Tribunal de Elecciones Municipales referencia alguna a esta ${ }^{83}$.

Esto movió al Tribunal a desarrollar él mismo elementos importantes concernientes a los aspectos procesales que no se encontraban detallados en leyes generales, y que cuando mucho encontraban algún apoyo en las leyes especiales que regían ciertas materias. Como se ha anticipado supra, las más importantes entre estas eran la ley que instauró al Tribunal en 1849, la reforma de 1861 a la Ley Municipal de 1854, y las leyes electorales de 1874 y 1884.

Un primer elemento que merece ser destacado entre estas cuestiones procesales se refiere al mecanismo para reclamar de este tipo de infracciones. Como se recordará de lo ya expuesto, las leyes aplicables señalaban que un reclamo era necesario, cuyo plazo de interposición fue primero de 15 días contados desde la instalación de la Municipalidad ${ }^{84}$, y luego de 8 días, reducido en la última configuración específica del proceso ${ }^{85}$. Se dio, sin embargo, el caso de que desde la propia municipalidad surgió una actividad que no era propiamente un reclamo, pero que implicaba un rechazo de la legalidad del acto realizado: la suspensión del escrutinio por detectarse anomalías, y que, como es obvio, había tenido lugar antes de la proclamación de los resultados. La controversia versó sobre si el Tribunal era competente para conocer de una cuestión suscitada por esta vía. En esta especie, el Tribunal zanjó la cuestión desde la óptica más abierta posible. Primero sostuvo que las razones "de baberse procedido de un modo irregularpor una de las Mesas Receptoras de aquel departamento, y la de no haber funcionado absolutamente otra mesa, entraña una verdadera reclamación de nulidad, y que esta reclamación ha sido además sostenida por el Ministerio público en cumplimiento del deber de velar por la observancia de las leyes, y de reclamar de los actos con que se las haya infringido", reconociendo entonces que un acto que no era formalmente una reclamación sí podía útilmente invocarse como tal,

\footnotetext{
${ }^{82}$ BLDG., I, p. 271.

${ }^{83}$ BLDG., XLIII, p. 543, sin texto completo, sino solo las modificaciones introducidas sobre el proyecto.

${ }^{84}$ Ley de 13 de septiembre de 1861, BLDG., XXIX, p. 204, art. 146; Ley de 12 de noviembre de 1874, BLDG., XLII, p. 317, art. 88.

${ }^{85}$ Ley de 9 de enero de 1884, BLDG., LIII, p. 59, art. 113.
} 
máxime si el propio Ministerio Público había secundado tal apreciación. Por ello, sostuvo el Tribunal, "si es verdad que la ley dispone que los reclamos de nulidad se inicien en el término perentorio de quince días después de la instalación de la nueva Municipalidad, tal disposición no puede estimarse aplicable sino a los casos en que se procede por acusación de parte y hay lugar a la instalación del Cabildo recién electo, pero no al caso presente, en que el incidente nacido del escrutinio ba venido a tomar posteriormente el carácter de un reclamo de nulidad" ${ }^{\prime \prime 6}$, con lo cual se entendía como lícito un procedimiento de nulidad electoral desencadenado con anterioridad al dies a quo señalado por la propia ley.

Años después, sin embargo, el Tribunal revirtió la jurisprudencia anterior, estimando que "la protesta y reserva de derechos que los reclamantes hicieron el 4 de mayo en la sesión de instalación, sometiéndose al fallo de la autoridad competente, no puede estimarse como una reclamación de nulidad para ante este Tribunal", que dicha protesta "no subsanaría la falta de reclamación tempestiva deducida ante el señor Juez. Letrado del departamento, o ante este Tribunal", y que tal solución se veía amparada en el hecho de que "si se diera a tales protestas el carácter de una reclamación de nulidad deducida en forma sin que ella fuese seguida de los procedimientos prescritos por el art. 78, se frustraría el propósito que persigue tanto ese artículo como el 90 de la misma ley, y podrían quedar las municipalidades durante todo el periodo legal de sus funciones afectadas por reclamos de nulidad ${ }^{87}$. En esta sentencia, sin embargo, se expresó una disidencia del Ministro Covarrubias, que expresaba que "esta cuestión fue planteada en el acto mismo de instalarse la nueva Municipalidad, y quedópara ser fallada por la autoridad correspondiente, según expresión del acta de instalación corriente a f. $\sigma^{\prime}$, y que, aun cuando la reclamación hubiera sido intempestiva, ello no podría obstar "para establecer la competencia de este Tribunal, competencia que trae su origen de la ley que lo creó, y no de la manera como los interesados ejercitan sus derechos ante ép'88.

En otro orden de materias, la jurisprudencia del Tribunal reconocía que los antecedentes de un juicio de nulidad electoral podían dar mérito a la prosecución penal respectiva si los hechos eran constitutivos de delito, cumpliéndose con los requisitos correspondientes ${ }^{89}$. Es interesante puntualizar que las leyes electorales originalmente no se refirieron a este tema. Recién la de 1874 introdujo una disposición al respecto, que preceptuaba que "la autoridad que declare nula una elección por actos que constituyan delitos públicos en materia electoral, mandará someter a juicio a los culpables. Sin esta orden, nadie podrá ser perseguido o enjuiciado por tales delitos" $"$. Como se advierte, la titularidad activa estaba sujeta a una restricción procesal muy importante, que posteriormente la ley de 1884 suprimió. De hecho, esta última reemplazó la disposición aislada de la ley de 1874 con un título completo, compuesto de nueve artículos y que se titulaba "De los procedimientos judiciales en materia electoral". En él se reconocía que "todas las faltas, delitos y crímenes electorales, producen

${ }^{86}$ TEM., 26 de octubre de 1870, Nulidad de elecciones municipales de Freirina, ANCE., 108, f. 115.

${ }^{87}$ TEM., 28 de noviembre de 1879, Nulidad de elecciones municipales de Quinchao, ANCE., 115, f. $352, D . O . n^{\circ} 817,6$ de noviembre de 1879 .

${ }^{88}$ ANCE., 115, f. 355.

${ }^{89}$ TEM., 11 de mayo de 1877, Nulidad de elecciones municipales de Lautaro, ANCE., 111, f. 477; TEM., 12 de junio de 1877, Nulidad de elecciones municipales de San Javier, D.O. $\mathrm{n}^{\circ}$ 89, 18 de junio de 1877.

${ }^{90}$ Ley de 12 de noviembre de 1874, BLDG., XLII, p. 317, art. 75. 
acción popular sin que el querellante esté obligado a rendir fianza ni caución alguna"91 y que "en materia electoral no se reconocen otros fueros que los establecidos por la Constitución"

Otro punto interesante es la apreciación de la prueba "como jurado" por parte del Tribunal, que ciertamente no era la regla procesal probatoria más habitual en esta época. Debe tenerse presente, en todo caso, que las elecciones municipales no eran una excepción en materia electoral, sino que desde la Ley de Elecciones de 1861 se estableció como un criterio común a todo tipo de reclamaciones en esta materia: "la autoridad llamada a conocer de los reclamos de nulidad, apreciará los hechos como jurado y según la influencia que a su juicio ellos hayan tenido en el resultado de la elección" "'. La fórmula fue reproducida idénticamente en las leyes electorales de $1874^{94}$ y de $1884^{95}$. Esta permanencia significó que el modo de apreciación fuera invocado en distintas sentencias $-\mathrm{y}$ también en votos disidentes ${ }^{96}-$ a fin de fundar la apreciación de los medios probatorios disponibles. La jurisprudencia del Tribunal intentó precisar el alcance de esta fórmula. Por ejemplo, una sentencia de 1886 sostenía que "este Tribunal, que tiene el deber de fallar como jurado y atendiendo solo a la verdad y a la justicia, estima, conforme a los dictados su conciencia que no puede declararse solamente la nulidad de la elección de los nueve municipales objetados en primer término, sino la de toda la municipalidad" ${ }^{\prime 97}$, entrelazando el elemento de la conciencia que no aparece en la descripción legal.

Esta flexibilidad en torno a la apreciación de la prueba no significaba, en todo caso, que la rendición de las pruebas estuviera exenta del cumplimiento de ciertas condiciones procesales. Así, el Tribunal censuró la presentación de elementos probatorios fuera de los cauces preestablecidos bajo el concepto de "irregular información"

En cuanto a la carga de la prueba, se trató de un aspecto sobre el que el Tribunal se pronunció en varias ocasiones. El principio generalmente aplicable era onus probandi incumbit actori, de acuerdo a los criterios generales; y, por lo tanto, la carga de la prueba de la infracción electoral recaía sobre el reclamante ${ }^{99}$. Por ello era determinante que no se hubiera presentado "prueba de ningún género para justificar los demás hechos apuntados en la solicitud elevada al Tribunal al tiempo de fallarse la presente reclamación" 100 ; o bien que la prueba no hubiera satisfecho la intensidad requerida, y por lo tanto no se hubieran "justificado legalmente los hechos en que se funda la reclama-

${ }^{91}$ Ley de 9 de enero de 1884, BLDG., LIII, p. 59, art. 116.

${ }^{92}$ Ley de 9 de enero de 1884, BLDG., LIII, p. 59, art. 117. Pero este artículo sí entendía regir la declaración del Consejo de Estado prevista en el artículo 104 n $^{\circ} 6$ de la Constitución de 1833.

${ }^{93}$ Ley de 13 de septiembre de 1861, BLDG., XXIX, p. 204, art. 128.

${ }^{94}$ Ley de 12 de noviembre de 1874, BLDG., XLII, p. 317, art. 74.

${ }^{95}$ Ley de 9 de enero de 1884, BLDG., LIII, p. 59, art. 94.

${ }^{96}$ Véase $A N C E ., 123$, f. 382 vta.

${ }^{97}$ TEM., 21 de octubre de 1886, Nulidad de elecciones municipales de Santiago, ANCE., 122, $\mathrm{f}$. 415, D. O. $\mathrm{n}^{\circ} 2844,27$ de octubre de 1886.

${ }^{98}$ TEM., 12 de junio de 1877, Nulidad de elecciones municipales de San Javier, D.O. $\mathrm{n}^{\circ}$ 89, 18 de junio de 1877.

${ }^{99}$ Muy claro en TEM., 20 de septiembre de 1888, Nulidad de elecciones municipales de Ancud, D. O. $\mathrm{n}^{\circ} 3405,27$ de septiembre de 1888 .

${ }^{100}$ TEM., 28 de abril de 1877, Nulidad de elecciones municipales de Vichuquén, ANCE., 111, f. 90. 
ción de nulidad"101, o que al menos ellos no se hubieran "justificado plenamente"102, o, en fin, que no se hubieran "presentado los datos necesarios para que este Tribunal pueda apreciar si la falta de elección en la sección de Queilen y las adulteraciones hechas en los registros electorales pudieran o no influir en el resultado general de la elección" ${ }^{\prime 103}$. Por ello es que las constancias que se dejaran en el momento mismo de verificarse la infracción, aun cuando no se tomaran como requisito de admisibilidad del reclamo, podían tener influencia decisiva en el resultado del procedimiento ${ }^{104}$, tal como también la tenía la presentación de las actas y otros documentos que pudieran esclarecer si la infracción había tenido influencia en el resultado general de la infracción ${ }^{105}$.

La mera enunciación de infracciones era insuficiente para dar lugar a la declaración de nulidad. El reclamante debía asimismo señalar con precisión qué candidatos se verían favorecidos con las infracciones respectivas, y la influencia que éstas podían ejercer en el resultado general de la elección ${ }^{106}$.

También debe tenerse presente que elementos probatorios que por sí solos no hubieran satisfecho la intensidad requerida en la carga de la prueba, aliados con otros sí podían dar por probada una determinada situación ${ }^{107}$. Con todo, el Tribunal reconocía, de manera algo oblicua, que no solo las partes podían presentar pruebas, sino que él también podía hacerlo, de modo de "suplir la deficiencia de la prueba rendida por las partes", salvo que el plazo fatal probatorio estuviese expirando ${ }^{108}$.

\section{La sentencia del juicio de nulidad}

Como aspecto central de los juicios sustanciados por el Tribunal de Elecciones Municipales, la sentencia que resolvía la cuestión de nulidad muestra tanto la extensión de la autoridad de este organismo como las posibilidades concretas de influir sobre el desarrollo de la función electoral en el Chile de la segunda mitad

${ }^{101}$ TEM., 4 de noviembre de 1880, Nulidad de elecciones municipales de Canquenes, ANCE., 114, f. 185, D. O. $\mathrm{n}^{\circ}$ 1090, 8 de noviembre de 1880. En igual sentido, TEM., 8 de octubre de 1885, Nulidad de elecciones municipales de Constitución, ANCE., 37, p. 27, ANCE., 124, f. 112, D. O. n ${ }^{\circ}$ 2541, 15 de octubre de 1885.

${ }^{102}$ TEM., 11 de septiembre de 1885, Nulidad de elecciones municipales de V aldivia, ANCE., 37, p. 29, ANCE., 120, f. 164 vta., D. O. n² 2522, 23 de septiembre de 1885.

${ }^{103}$ TEM., 10 de octubre de 1885, Nulidad de elecciones municipales de Castro, ANCE., 37, p. 36, ANCE., 119, f. 239, D. O. n² 2553, 29 de octubre de 1885.

${ }^{104}$ TEM., 29 de octubre de 1879, Nulidad de elecciones municipales de Copiapó, ANCE., 113, f. 47; TEM., $1^{\circ}$ de octubre de 1888, Nulidad de elecciones municipales de Lebu, ANCE., 124, f. 369, D. O. $\mathrm{n}^{\circ} 3412,5$ de octubre de 1888 .

${ }^{105}$ TEM., 27 de septiembre de 1888, Nulidad de elecciones municipales de Temuco, D. O. $\mathrm{n}^{\circ} 3407$, 29 de septiembre de 1888.

${ }^{106}$ TEM., 15 de abril de 1880, Nulidad de elecciones municipales de Chillán, D. O. n 921, 16 de abril de 1880 .

${ }^{107}$ TEM., 12 de junio de 1877, Nulidad de elecciones municipales de San Javier, D.O. $\mathrm{n}^{\circ}$ 89, 18 de junio de 1877: "aun cuando este hecho, estimado aisladamente, no podría servir de fundamento para declarar la nulidad de la elección, apreciado en conjunto con los demás, es otro comprobante de la irregularidad con que en general se ha procedido en dicha elección".

${ }^{108}$ TEM., 31 de agosto de 1880, Nulidad de elecciones municipales de Constitución, ANCE., 114, f. 367, D. O. $\mathrm{n}^{\circ} 1039,4$ de septiembre de 1880 . 
del siglo XIX. Una revisión de las sentencias muestra elementos de considerable sofisticación técnica ${ }^{109}$.

Desde un punto de vista político, las causas más notables del conjunto son las que declararon nulidades $\mathrm{m}$ ú $1 \mathrm{t}$ i p 1 e s. Esta multiplicidad se dio en dos sentidos diferentes.

Por una parte, era posible la declaración de nulidad múltiple s i m u l t á n e a. Esta podía verificarse en aquellos casos en que un mismo acto electoral hubieran coexistido dos procesos electorales distintos. Esta situación, ya a primera vista gravemente anómala, fue objeto de una sentencia de 1870 en la cual se ventiló la situación de que una elección terminase creando dos municipalidades paralelas en la ciudad de Cauquenes. Aquí claramente había existido alguna infracción, pero la cuestión pasaba por determinar cuál de las dos municipalidades sería la ilegal frente a la otra que habría sido electa conforme a derecho, o bien, en el caso más drástico, determinar que en definitiva ambas municipalidades electas eran ilegales. Desde el punto de vista de la iniciativa del procedimiento, se habían interpuesto reclamaciones cruzadas de una facción contra la otra, lo que motivó, como es esperable, la expresión de catálogos de infracciones respecto de cada uno de los actos electorales. Siguiendo el dictamen fiscal, el Tribunal de Elecciones Municipales declaró simultáneamente la nulidad de ambas municipalidades.

En primer lugar, respecto de la elección que había sido organizada por la municipalidad hábil, estaba claro que aquella se había realizado "funcionando solo tres de las seis mesas receptoras que debian recibir los sufragios de los electores del departamento" (considerando quinto), y que dichas mesas "solo funcionaron por espacio de una hora, poco más o menos" (considerando séptimo), con lo que se constataban infracciones palmarias; y ellas habían tenido influencia en el resultado general de la elección, en atención a que "el total de los sufragios recibidos en favor de la indicada lista ascendió unicamente a doscientos sesenta y tres votos, siendo que el total de los ciudadanos calificados asciende a más de ochocientos" (considerando octavo). Y, por su parte, respecto de la elección "b", la cuestión era aún más radical, pues ella había sido "becha por las mesas receptoras nombradas ilegalmente por una municipalidad inhábil' (considerando décimo), compuesta de "miembros de la municipalidad anterior, de la antepretérita y de otros ciudadanos que habian tenido ese cargo en épocas todavía mucho más atrasadas"

${ }^{109}$ Aunque, por cierto, también se encuentran aspectos muy cuestionables. Quizás la sentencia que más fácilmente pudiera ser objeto de crítica, desde un punto de vista procesal, es TEM., 31 de agosto de 1880, Nulidad de elecciones municipales de Constitución, ANCE., 114, f. 367, D. O. $\mathrm{n}^{\circ} 1039,4$ de septiembre de 1880, que termina expresando en el dispositivo lo siguiente: "no ha lugar a las reclamaciones de nulidad ni a la declaración de validez a que se refieren las solicitudes de don Urcisinio Espejo, don Laureano Castillo y don José Basilio Aravena". Este dispositivo insólito se derivaba de una controversia en la que el Tribunal no hallaba mérito para declarar la nulidad de ciertas elecciones, y que, solicitada la declaración de validez de las mismas, en lugar de proceder a declararla, estimaba que "tampoco aparece comprobada la validez de la elección". Como se advierte, el Tribunal confundió la carga de la prueba con la regla de juicio, con lo cual terminó faltando a su deber de resolver la cuestión. Sobre esta materia, en juicios referidos a la nulidad, véase Bocksang Hola, Gabriel, La carga de la prueba de la nulidad de un acto administrativo, en ArANCIBIA, Jaime - Martínez, José Ignacio - Romero, Alejandro (eds.), Litigación pública (Santiago, AbeledoPerrot, 2011), pp. 217-244, especialmente pp. 234-236. 
(considerando duodécimo), y que, por lo demás, el acto se había desarrollado "sin tener a la vista el original del registro electoral del departamento, y con solo una copia destituida de las autorizaciones requeridas por la ley para considerarla fehaciente en ciertos casos" (considerando decimotercero). Constatados todos los vicios anteriores, el Tribunal no pudo sino declarar "nulas las dos elecciones de municipales verificadas en Cauquenes el día 17 de abril del corriente año" "110, reforzando, por lo demás, la idea de una concepción integral de la legalidad ${ }^{111}$. En síntesis, si una autoridad legítima obraba antijurídicamente, su actuación era nula.

$\mathrm{Y}$, en segundo lugar, si existía una autoridad ilegítima que organizase un acto electoral, su actuación era de por sí nula en razón de su origen espurio; a lo que se sumó, en la especie de marras, el hecho de que tampoco se había cumplido procedimentalmente con los requisitos de un acto de esta naturaleza. Se advierte que en esta decisión giran varias ideas que ya estaban presentes en la concepción chilena de la legalidad en el siglo XIX: la autoridad legítima, los requisitos procedimentales y los requisitos de forma como elementos centrales para la validez de las actuaciones en el derecho público ${ }^{112}$, reconociéndose en el derecho público, entonces, la importancia tanto de una juridicidad ontológica como de una juridicidad operativa.

A más de las nulidades múltiples simultáneas, en la jurisprudencia del Tribunal de Elecciones Municipales se advirtió un segundo tipo de nulidades múltiples: las s u c e s i v a s. No se trataban estas de las nulidades consecuenciales, o nulidades por carambola, en las que la declaración de nulidad de un acto anterior trae como efecto la nulidad de aquellos actos que se apoyaban sobre el primero declarado nulo ${ }^{113}$, sino que versaban sobre la posibilidad de que un acto realizado en ejecución de una declaración anterior de nulidad pudiera ser también declarado nulo, por vicios inherentes a él. En lo técnico, la fórmula no tiene nada de extraño, dado que se somete a los criterios básicos aplicables sobre la nulidad; pero en lo político esta figura ciertamente significaba una decisión inusual del Tribunal, que conllevaba declarar nula una elección que se había practicado tras ya haberse declarado nula otra anterior.

Esta situación, única en la jurisprudencia del Tribunal, se dio en una especie de 1884. Las elecciones de la municipalidad de Vallenar celebradas en 1882 habían sido declaradas nulas a inicios de $1883^{114}$, sentencia en la cual se ordenó proceder a nueva elección. Esta se verificó a fines del mes siguiente, y dio lugar a una nueva reclamación de nulidad. Tramitada, el Tribunal constató que "la junta receptora de la primera sección funcionó ilegalmente, por haberse instalado al día siguiente del de

${ }^{110}$ TEM., 25 de agosto de 1870, Nulidad de elecciones municipales de Canquenes, ANCE., 108, f. 393 .

${ }^{111}$ La censura de la realización simultánea de dos actos electorales se prolongó posteriormente en TEM., 27 de octubre de 1879, Nulidad de elecciones municipales de Carelmapu, D. O. $\mathrm{n}^{\circ}$ 795, 11 de noviembre de 1879.

${ }^{112}$ Bocksang Hola, Gabriel, El nacimiento, cit. (n. 28), pp. 574-581.

${ }^{113}$ Bocksang Hola, Gabriel, L'inexistence juridique, cit. (n. 28) pp. 494-499.

${ }^{114}$ TEM., 12 de enero de 1883, Nulidad de elecciones municipales de Vallenar, ANCE., 118, $\mathrm{f}$. 49, D. O. n n $^{1729,} 15$ de enero de 1883. 
las elecciones, sin que ocurriera ninguna de las circunstancias que indica la ley para autorizar ese procedimiento, y por haber funcionado sin el número de vocales que exige el artículo 37 de la ley de elecciones" y que dicha infracción había influido en el resultado general de la elección (considerandos primero y segundo). Por consiguiente, esta segunda elección también fue declarada nula, lo que implicaba la realización de una tercera elección ${ }^{115}$.

También exploró el Tribunal de Elecciones Municipales la figura de la nulidad p a r c i a l, que en estos casos implicaba pronunciarla respecto de algunos municipales, declarándose al mismo tiempo que los restantes habían sido lícitamente escogidos. Bajo el régimen de la ley municipal de 1854, el Tribunal no vaciló en integrar esta posibilidad.

Así, por ejemplo, en 1870 se declaró nula la elección de un solo municipal, manteniéndose los otros electos, en atención a que la mesa en la que se había constatado la infracción hubiera podido cambiar solamente el resultado del último de los electos, y por lo tanto, se declaró "válida la elección de Municipales del departamento de Freirina hecha en abril del presente año, respecto de los siete municipales propietarios, y tres municipales suplentes primeramente nombrados, y nula respecto de don Nereo Guerrero nombrado en octavo lugar" ${ }^{\prime 16}$. Para fundar la posibilidad de declarar la nulidad parcial, el Tribunal invocó la ley municipal de 1854, cuyo artículo 11 inciso tercero disponía que "si la nulidad se hubiere declarado respecto de alguno o algunos de sus miembros solamente, se integrará la Municipalidad llamando a los suplentes elegidos, y a falta de éstos, a los miembros de municipalidades anteriores según el orden prescrito en el final del párrafo precedente" 117 .

Como se advierte, el tenor literal de la disposición era inequívoco en torno a poderse declarar la nulidad parcial, lo que motivó probablemente que hasta finales de la vigencia de dicha ley municipal se articularan en las contiendas sobre esta materia pretensiones subsidiarias de nulidad total y nulidad parcial ${ }^{118}$. Pero debe tenerse presente que la norma de la ley de 1854 que mencionaba la posibilidad de nulidades parciales o totales no reapareció en la ley municipal de $1887^{119}$, lo que quizás incidió en el cambio de jurisprudencia operado en 1888 en las postrimerías del Tribunal en relación con la influencia sobre el resultado general de la elección ${ }^{120}$, a que hemos hecho referencia $s u p r a^{121}$, y que muestra una clara tendencia a menoscabar la posibilidad de declarar nulidades parciales.

115 TEM., 10 de enero de 1884, Nulidad de elecciones municipales de Vallenar, ANCE., 118, f. 417, D. O. n ${ }^{\circ} 2028,16$ de enero de 1884 , dispositivo.

${ }^{116}$ TEM., 26 de octubre de 1870, Nulidad de elecciones municipales de Freirina, ANCE., 108, f. 115.

${ }^{117}$ Ley de 8 de noviembre de 1854, BLDG., XXII, p. 616.

${ }^{118}$ Muy claramente en TEM., 21 de octubre de 1886, Nulidad de elecciones municipales de Santiago, ANCE., 122, f. 415, D. O. n ${ }^{\circ}$ 2844, 27 de octubre de 1886, en la que finalmente se declaró la nulidad total, estimando el Tribunal, "conforme a los dictados de su conciencia, que no puede declararse solamente la nulidad de la elección de los nueve municipales objetados en primer término, sino la de toda la municipalidad, como se solicita subsidiariamente en la reclamación de f. 1"' (considerando séptimo).

${ }^{119}$ Ley de 12 de septiembre de 1887, BLDG., LVI, p. 1351.

${ }^{120}$ TEM., 29 de septiembre de 1888, Nulidad de elecciones municipales de Melipilla, ANCE., 123, f. $277, D . O . \mathrm{n}^{\circ} 3411,4$ de octubre de 1888 .

${ }^{121}$ Sección I.2. 
También tiene gran relieve en esta materia la determinación de los efectos de la declaración de nulidad. En lo sustancial, durante casi toda la vigencia del Tribunal estos se vieron regidos por el artículo 11 de la Ley de Municipalidades de 1854, organizado en torno a distinguir el momento en que se declarase la nulidad de la elección. Su primer inciso preceptuaba lo siguiente: "si se bubiese declarado nula por el tribunal competente, la elección de una Municipalidad y esta declaración se expidiere durante los primeros dieciocho meses de su periodo constitucional, se procederá a nueva elección". Por el contrario, "si el caso ocurre pasado este término", añadía el inciso segundo, "entrarán a funcionar como municipales los que lo bubieren sido en las municipalidades anteriores, prefiriendo los de la más cercana a los de las más remota, y entre los de una misma según el orden de precedencias" ${ }^{122}$.

Con todo, una ley complementaria de la Ley de Elecciones de 1874 vino a modificar el cuadro anteriormente planteado, disponiendo lo siguiente: "declarada nula por el tribunal competente la elección de una Municipalidad o de un tercio de los miembros que deben legalmente componerla, se procederá a nueva elección dentro del término fijado en el inciso $1^{\circ}$ del art. 80" ${ }^{123}$. Dado que los artículos 88 a 91 de la ley de 1874 no señalaban los efectos de la declaración de nulidad, lo que esta norma disponía, coordinándola con la ley municipal de 1854, era (i) un nuevo reconocimiento de la procedencia de declarar una nulidad parcial, y (ii) el establecimiento de un límite entre los vicios que daban lugar a realizar una nueva elección y los que no, frontera que se fijaba en un tercio de la Municipalidad. De la entrada en vigor de la norma quedaban aspectos ambiguos, como el de qué sucedía en los casos en que los municipales declarados nulos hubieran sido inferiores a un tercio, lo que probablemente originó que esta norma apenas fuera invocada dos veces por el Tribunal ${ }^{124}$; y que, en la Ley Electoral de 1884, la figura se simplificara y la redacción se cambiara totalmente, señalándose que habría necesariamente nueva elección, y remitiéndose a las disposiciones que regían las elecciones de senadores y diputados para tal situación: "en caso de declaración de nulidad, la nueva elección se verificará en el plazo y forma indicados en los artículos 101 y $102 " 125$.

Por último, hay aspectos puntuales pero significativos que pueden dar cuenta de la amplitud de aspectos tenidos en cuenta por el Tribunal. El primero es que este, en alguna oportunidad en que no halló mérito para declarar la nulidad del acto electoral y realizar una nueva elección, sí se entendió competente para declarar la nulidad de un escrutinio y proclamar por sí los resultados que estimaba ser conformes a derecho ${ }^{126}$. Y el segundo es que el Tribunal de Elecciones Municipales prescindió de disposiciones legislativas y administrativas vigentes que entendió ser contrarias a la Constitución ${ }^{127}$, lo que reviste especial importancia en relación

${ }^{122}$ Ley de 8 de noviembre de 1854, BLDG., XXII, p. 616.

${ }^{123}$ Ley de 11 de agosto de 1875, BLDG., XLIII, p. 258.

${ }^{124}$ TEM., 11 de mayo de 1877, Nulidad de elecciones municipales de Lautaro, ANCE., 111, f. 477; TEM., 4 de noviembre de 1879, Nulidad de elecciones municipales de Copiapó, ANCE., 114, f. 88.

${ }^{125}$ Ley de 9 de enero de 1884, BLDG., LIII, p. 59.

${ }^{126}$ TEM., 20 de noviembre de 1882, Nulidad de elecciones municipales de Talca, ANCE., 116, $\mathrm{f}$. 200, D. O. n 1689, 22 de noviembre de 1882.

${ }^{127}$ En dos sentencias distintas referidas a un mismo proceso eleccionario: TEM., 20 de 
con el razonamiento normativo y la geometría que a la sazón se le reconocía al ordenamiento jurídico.

Y por más que la solución de este Tribunal en tal materia constitucional se halle articulada con la existencia de otras disposiciones complementarias de interés para resolver la cuestión - desechándose en la especie la declaración de nulidad-, se trata de una argumentación de inequívoca importancia, que controvierte totalmente la idea de que en el siglo XIX la Constitución no tenía operatividad determinante en cuestiones prácticas. La había tenido desde la época de los primeros textos constitucionales, incluso ante los tribunales ordinarios ${ }^{128}$, a lo que no se sustrajo un tribunal especial posterior como el que ha sido objeto de estas líneas.

\section{CONCLUSIÓN}

Estas líneas han procurado analizar el impacto que tuvo la actividad del Tribunal de Elecciones Municipales desde un punto de vista estrictamente jurídico. No ha sido objeto de este artículo el impacto político que ella haya tenido sobre el país - a nivel nacional, local, o de los partidos o movimientos políticos de la época-, que quedará para el análisis de especialistas en las disciplinas respectivas.

En lo que concierne al derecho, conviene destacar que, a través de varias decenas de expedientes y sentencias, el Tribunal desarrolló una labor muy interesante desde el punto de vista jurídico, tanto en aspectos sustantivos (I) como en aspectos procesales (II). Ambos grupos de cuestiones proyectan su influencia tanto desde un punto de vista institucional como desde uno dogmático.

En primer lugar, i n s t i t u c i o n a $1 \mathrm{~m}$ e n t e, esta labor jurisprudencial constituye un aspecto relevante en el estudio del derecho administrativo -así como su rama específica del derecho municipal-, del derecho electoral, y del derecho procesal chileno. En tal faena puede percibirse un sentido general de continuidad, que parece no haberse visto radicalmente afectado por los cambios de leyes electorales. En los contados casos en que hubo alteraciones en las líneas jurisprudenciales, en ello no parece haber existido influjo de cambios legislativos; por ejemplo, cuando el tribunal mutó - a fines del período- su enfoque en torno a la influencia en el resultado general de la elección como requisito para la declaración de nulidad.

$\mathrm{Y}$, en segundo lugar, d o g m á t i c a m e n t e, la jurisprudencia del Tribunal ofrece un ejemplo de desarrollo temprano de una esfera específica de invalidez en el ámbito del derecho público. Las sentencias y los expedientes muestran con claridad tanto la relevancia de la labor del Tribunal de Elecciones Municipales como las dificultades técnicas a las que debió enfrentarse para resolver las cuestiones: baste tener presente -por no destacar sino las más llamativas- las situaciones de nulidades sucesivas o múltiples, el delineamiento del requisito de influencia en el resultado general de la elección, y la determinación de los tipos de vicios

septiembre de 1888, Nulidad de elecciones municipales de Valdivia ( $1^{a}$ sentencia), D. O. $\mathrm{n}^{\circ} 3406,28$ de septiembre de 1888; y TEM., 20 de septiembre de 1888, Nulidad de elecciones municipales de Valdivia (2a sentencia), D. O. $\mathrm{n}^{\circ} 3406,28$ de septiembre de 1888.

${ }^{128}$ Bocksang Hola, Gabriel, El nacimiento, cit. (n. 28), pp. 35-50. 
conducentes a la declaración de nulidad. Aunque el desempeño del Tribunal no resulta exento de críticas, sí se advierte un celo especial en abordar una materia difícil, desarrollando criterios susceptibles de ser tomados en consideración por los órganos de justicia electoral existentes con posterioridad a su desaparición, y que, al menos en parte, incluso en nuestros días podrían ser aprovechados útilmente en materias de nulidad electoral.

BiBLIOGRAFÍA

Bocksang Hola, Gabriel, La carga de la prueba de la nulidad de un acto administrativo, en Arancibia, Jaime - Martínez, José Ignacio - Romero, Alejandro (eds.), Litigación pública (Santiago, AbeledoPerrot, 2011), pp. 217-244.

—L'inexistence juridique des actes administratifs (Paris, Mare \& Martin, 2013).

-El nacimiento del derecho administrativo patrio de Chile (Santiago, Thomson Reuters, 2015), pp. 574-581.

-Voidness and voidability of unilateral administrative acts in the Western Tradition, en RosEAckerman, Susan - Lindseth, Peter L. - Emerson, Blake (eds.), Comparative Administrative Law (2nd ed., Cheltenham, Edward Elgar, 2017), pp. 420-434.

Bravo Lira, Bernardino, Historia de las instituciones politicas de Cbile e Hispanoamérica (Santiago, Editorial Jurídica de Chile, 1986).

—El Estado de Derecho en la Historia de Chile (Santiago, Ediciones Universidad Católica de Chile, 1996).

Castilla, Aurelio, Jurisprudencia del Consejo de Estado (Parral, Imprenta La Democracia, 1919).

Eyzaguirre Gutiérrez, Jaime, Historia constitucional de Chile (Santiago, Editorial Universitaria, 1966).

Heise GonzÁlez, Julio, Historia constitucional de Chile (Santiago, Editorial Jurídica de Chile, 1959).

Huneeus Zegers, Jorge, La Constitución ante el Congreso (Santiago, Imprenta de los Tiempos, 1880).

Jara Reyes, René, Regularidad electoral, secreto de voto y exclusión. Las tesis dominantes en las memorias de prueba sobre el sufragio en Chile (1897-1920), en REHJ., 39 (Valparaíso, Chile, 2017), pp. 329-349.

LARRAín ZaÑarTU, Ignacio y Joaquín, Boletín de las principales leyes y decretos vigentes dictados desde enero $1^{\circ}$ de 1860 basta enero $1^{\circ}$ de 1871 (Valparaíso, Imprenta del Mercurio, 1871).

NaZer Ahumada, Ricardo, Las finanzas municipales cbilenas: 1833-1887, en Historia, 32 (1999), pp. 265-314.

Ponce de León Atria, Macarena, Estado y elecciones. La construcción electoral del poder en Chile, siglos XIX y XX, en Jaksić, Iván - Rengifo, Francisca (eds.), Historia politica de Chile, 1810-2010. Tomo II: Estado y Sociedad (Santiago, Fondo de Cultura Económica, 2017), pp. 243-270.

Prado Bustamante, Santiago, Principios elementales de derecho administrativo chileno (Santiago, Imprenta Nacional, 1859).

Rengifo Streeter, Francisca, Poder municipal. La territorialización del gobierno estatal en Chile, 1830-1890, en Palimpsesto, 10, n 17 (2020), pp. 247-266.

Salazar Vergara, Gabriel, Historia del municipio y la soberanía comunal en Chile, 1820-2016 (Santiago, Editorial Universitaria, 2019). 
Urzúa Valenzuela, Germán, Evolución de la administración pública chilena (Santiago, Editorial Jurídica de Chile, 1970).

Urzúa Valenzuela, Germán, Historia politica de Chile y su evolución electoral (desde 1810 hasta 1992) (Santiago, Editorial Jurídica de Chile, 1992).

Valenzuela, Arturo, Political Brokers in Chile: Local Government in a Centralized Polity (Durham, Duke University Press, 1977).

VALENZUELA, Julio Samuel, Hacia la formación de instituciones democráticas: prácticas electorales en Chile durante el siglo XIX, en Estudios Públicos, 66 (1997), pp. 215-257.

—La ley electoral de 1890 y la democratización del régimen político chileno, en Estudios Públicos, 71 (1998), pp. 265-296.

VILA, Bernardino Antonio, Prontuario de los juicios (Santiago, Imprenta de la Sociedad, 1858). 